\title{
Use of Information Technology by Nurses in Private Hospitals in the State of Tamil Nadu in India
}

\author{
Brijendra Singh ${ }^{1}$ \\ Senthil J.2 \\ ${ }^{1}$ School of Information Technology and Engineering, VIT University, Vellore, Tamil Nadu, India \\ 2School of Computer Science and Engineering, VIT University, Vellore, Tamil Nadu, India
}

\section{Doi:10.5901/mjss.2015.v6n4s2p658}

\begin{abstract}
The aim of the study was to assess the comfort level and frequency in the use of information technology (IT) among nurses and analyze the relationship between various factors governing their use. A survey was conducted during 2013-14 at select Indian Hospitals of Tamil Nadu State. Correlation analysis and ANOVA test were used to analyze the data. The nurses working in the medium sized hospitals in the State are the study population. A random sample of 600 nurses was selected for the study. Gender, qualification and age level were analyzed to found the influence on use of computer hardware, communication and administrative related activities using computers. Effective and majority use of computers for information processing activities, communication, planning and policy development activities, finance, administration, education and research can lead healthcare organization to run their processes efficiently. Hospitals can provide appropriate computer training programs and computers access to nurses to realize the benefits from IT. Healthcare professionals may encourage nurses to use IT and computers at their work place by providing them attractive incentives.
\end{abstract}

Keywords: IT (Information Technology), EHR (Electronic Health Record), PACS (Picture Archiving of Communication System), RIS (Radiology Information System), Clinical Decision Support System (CDSS), PDA (Personal Digital Assistant), Policy.

\section{Introduction}

Nurses are the major human resource in any healthcare organization. It is not possible to improve the performance of healthcare organization without them. There is no doubt that effective use of information technology by nurses will enhance the performance of nurses in healthcare by improving workflow and by reducing medical errors. Many studies have been done in other countries to assess the comfort level and frequency in use of information technology by nurses, but very few studies are available in the Indian context in private hospitals. This study is to fill this gap. The study has been done in medium sized select private hospitals of Tamil Nadu. The objective of the study is to study the knowledge and comfort level in the use of computers and information technology (IT) among nurses in private hospitals in Tamil Nadu. It also analyzes the factors that promote their use of information technology and computers and attempts to find the relationship between various factors governing their use.

Computers play a vital role in the documentation, administration of patient's health and medical information and communication within and outside the healthcare organization. Patients' health information is stored in computers, and accessed by nurses and doctors quickly and conveniently. Patient health information like X-rays, CT scans can be easily transferred from one department to other and can be viewed on any computer. This inter departmental exchange of patient information facilitates faster patient care and pooling of patient information from different locations in one centralized location. This exchange of patient information is not restricted to inter departments only but also possible between hospitals, in case patient changes his treatment location. Nurses can use computers for resources and personnel management, so that manpower and other resource requirements can be efficiently distributed for the effective patient care, and management.

The purpose of this study was to measure the significant difference between male and female, bachelor and diploma holder and different age group nurses in use of information technology and to find the correlation among various information technology aspects such as hardware, operating system, information processing activities, communication, patient related information, advantages of using computers, planning and policy development, education and research, financial activities and administration. 


\subsection{Literature Review}

A study done in Australia (Robert Eley et al.2005) estimated that $86 \%$ nurses used computers in their workplace. They were using computers mainly for accessing patient related information, for communication, for updating their medical knowledge, and for professional development and policy access. About $25 \%$ of the nurses stated that they were very confident in the use of software applications.

Another study done in a UK hospital to identify the use of computer databases by nurses for incorporating evidence based practice found that there was a low level of confidence in the use of databases (Peter Griffiths et al. 2001). $27 \%$ nurses reported the use of the system, Cumulative Index to Nursing and Allied health Literature (CINAHL), $18 \%$ reported the use of Medical Literature Analysis and Retrieval System Online (MEDLINE) and a very few nurses used Cochrane Library. It found that there was a need for the courses taught in nursing curriculum to be more specific on technology usage and evidence based learning. It also found that the Evidence based practice allowed healthcare staff to access the advanced clinical information electronically.

A study done at a psychiatric hospital in Finland on the acceptance and utilization of IT by nurses found that work processes and delivery care are affected due to the limited use of IT (Marita Koivunen et al. 2009). Acceptance of IT could be improved if the hospital focused on the factors such as IT learning, computer skills, teamwork, training, nurse and patient affiliation, usefulness of IT application and use of new software in psychiatric hospitals. The study also reported that experience in using computers and motivations to use were significantly correlated. Male nurses who attended the professional and IT application training courses were found to be more experienced in IT implementation process compared to the female nurses. Participation in IT implementation process was compared between younger nurses and older nurses. It was found that the younger nurses were more adaptable to using computers.

Another study done in a teaching hospital in Nigeria to assess the use of computers and internet by nursing students found that $58 \%$ of nursing students were computer literate (Grace Ada Ajuwon et al. 2003). Electronic mail (Email) and Microsoft Word were the popular tools used by nursing students. The study suggested that computer education must be included in nursing curriculum and computer laboratories must be set up in order to facilitate the nursing students' use of computers.

A study done in the USA (Dumas JA et al. 2001) to find the extent of use of computer technologies by nurses showed that $83 \%$ of nurses used computers in their workplace. They used computers mainly for creating and accessing patient related information and searching the websites to update their knowledge. The primary focus of computer applications was to improve patient care.

According to a study done at the Hospital of Ludhiana, Punjab, India (Emans Evangel Joel Raja et al. 2004), 75\% nurses possessed good knowledge of computers and 100\% nurses have had positive attitude towards use of computers.

Basic computer knowledge and skills were found to be essential to use information technology in health care industry. Nurses needed to be more innovative, resilient and problem solvers to use computers efficiently and effectively at their work place. Efficient use of computers improved nursing practice and patient care, leading to the desired outcomes (Jane Peace et al. 2011).

A study done in the USA (Mona P. Ternus et al. 2008) found that the computer literacy was prevalent among nursing students. It also found that high computer literacy was present among the students who owned computers compared to those who did not own computers. It also found that computer literacy level increased with the younger incoming fresh set of students. A study done at a national hospital in Kenya (L. W. Kivuti-Bitok et al. 2009) on nurse managers found that the nurses had positive attitude towards the use of computers. However, older nurses exhibited lack of interest in use of computers.

A study done in Sweden (Hans Ragneskog et al. 2006) on nursing students and nursing educators to assess their experiences, attitudes and skills in use of IT found that majority of them used computers at their homes. About $71 \%$ of nursing students reported that they had good computer knowledge and IT skills needed for their current and future requirements. On the other hand, nurse educators reported that only $29 \%$ of nursing students possessed good computer knowledge and IT skills. It also reported that $48 \%$ of nurse educators possessed adequate IT skills. The study suggested that IT skills should be included in nursing curriculum. A good computer infrastructure is needed for effective IT curriculum.

\section{Methodology}

For this study, survey research methods were employed for collecting the data. Descriptive and inferential statistical techniques were used to analyze the data. Nurses working in medium select sized hospitals formed the study population. 
A random sample of 600 nurses was selected for the study. 164 nurses responded to the survey. Out of the total respondents, $14.63 \%$ were married and $85.37 \%$ were unmarried, $60.98 \%$ possess bachelor degree and $39.02 \%$ were diploma holder nurses, $60.36 \%$ were $20-25$ years, $23.79 \%$ were $26-30$ years and $15.85 \%$ were $31-50$ years old. The demographic information of the respondents is shown in table-1.

Table 1. Demographics

\begin{tabular}{|l|c|c|c|c|c|c|c|}
\hline \multirow{2}{*}{ Respondents } & \multicolumn{2}{|c|}{ Sex } & \multicolumn{2}{c|}{ Qualification } & \multicolumn{3}{c|}{ Age(In years) } \\
\cline { 2 - 8 } & Male & Female & Bachelors & Diploma & $\mathbf{2 0 - 2 5}$ & $\mathbf{2 6 - 3 0}$ & $\mathbf{3 1 - 5 0}$ \\
\hline Number of respondents $(\mathbf{N}=164)$ & 24 & 140 & 100 & 64 & 99 & 39 & 26 \\
\hline Percentage of respondents & 14.63 & 85.37 & 60.98 & 39.02 & 60.36 & 23.79 & 15.85 \\
\hline
\end{tabular}

\section{Data Analysis}

SAS 9.3 version was used to analyze the data. Analysis of variance technique is used to find the significance difference between male and female in use of technology. Correlation technique was used to find the relationship between various aspects and issues.

The aspects and issues explored in this study are hardware, operating systems, information processing, communication, advantages of using computers, patient related information, planning and policy development, finance, administration, education and research, software, application, personal and computer hardware related issues. There are 13 aspects and 2 issues that are studied. The description of these aspects and issues are given in table-2. It describes the various components studied under these aspects and issues. For example the aspect "Hardware" covers components like Desktop, Laptop, Ipad, keyboard, Mouse, Touch screen, handheld PDA's, USB devices (pen drives), Printer and Bar codes.

Table 2. Description of information technology aspect/issues studied

\begin{tabular}{|c|c|}
\hline Aspect/lssues & Description \\
\hline Hardware & $\begin{array}{l}\text { Desktop, Laptop, Ipad, keyboard, Mouse, Touch screen, handheld PDA's, USB devices (pen drives), Printer } \\
\text { and Bar codes. }\end{array}$ \\
\hline Operating System & Windows XP, Vista 7 and UNIX etc. \\
\hline Information Processing & Microsoft Word, Excel Sheet and Power Point Presentation \\
\hline Communication & Email, Web Browser, Communication within and outside the organization \\
\hline Advantages of using computers & $\begin{array}{l}\text { Time saving, Job easiness, Easy access to information, Less medical errors, Improved clinical workflow, } \\
\text { Administrative support, Better quality of service. }\end{array}$ \\
\hline Patient related information & $\begin{array}{l}\text { Storing and accessing patient information, Diagnosis test/results, Patient hospitality management, } \\
\text { Documentation of patient/clinical information, Resolving patient complaints }\end{array}$ \\
\hline Planning and policy development & $\begin{array}{l}\text { Clinical Decision support system(CDSS), Patient care planning, policy development, Hospital services and } \\
\text { planning, Health marketing and management, Maintaining health information system, Quality assurance }\end{array}$ \\
\hline Finance & Finance applications, Budgeting, Ensuring human resources \\
\hline Administration & Administrative/clinical work, Administrative record \\
\hline Education and Research & Education, Training and Research \\
\hline Personal Issues & $\begin{array}{l}\text { Age, Workload, Lack of training, Uncomfortable in front of patients/relatives, Other workload, Concern about } \\
\text { health, Lack of confidence, Lack of knowledge, Lack of interest. }\end{array}$ \\
\hline Computer hardware related issues & $\begin{array}{l}\text { Slow speed, Lack of availability of computers, Priority to senior employees, Lack of encouragement by } \\
\text { employer }\end{array}$ \\
\hline Software & $\begin{array}{l}\text { Knowledge based system, Simulation tools, EHR (Electronic Health Record), PACS (Picture Archiving of } \\
\text { Communication System), RIS (Radiology Information System), Patient/client management system (e.g. } \\
\text { DoctorSahab), Employee Management(e.g. PeopleSoft) }\end{array}$ \\
\hline Applications & $\begin{array}{l}\text { Bar code medication system, PDA (Personal Digital Assistant), Monitoring system, Financial management, } \\
\text { Telehealth system }\end{array}$ \\
\hline
\end{tabular}

\subsection{Correlation Analysis}

A correlation analysis was run for various aspects of using computers. Information processing activities were highly correlated with the use of hardware (Pearson Correlation Coefficient $r=0.84009)$ and with operating system $(r=0.72502)$. If nurses are more comfortable in using desktop, laptop, Ipad, keyboard, mouse, touch screen, handheld PDA's, USB devices (pen drives), printer and bar codes, then obviously they will be more comfortable in using information processing 
tools such as Microsoft Word, Excel Sheet and Power Point Presentation etc. Level of comfort in use of operating system like Windows XP, Vista 7 and UNIX etc leads to more use of information processing activities like Microsoft Word, Excel Sheet and Power Point Presentation; so if the operating system is user friendly and easy to use, then information processing activities can be increased.

Communication related activities were highly correlated with advantages of using computers $(r=0.87215)$, with finance $(r=0.83154)$, with administrative activities $(r=0.72363)$ and with education and research $(r=0.80447)$. Advantages of using computers can be realized by nurses after using the communication tools effectively. Hence, communication related activities should be enhanced in working environment in order to realize the benefit comes after using the computers frequently. Financial activities using computers can become easier if communication within and outside the organization will be in effective way. Education and research can be encouraged with the help of communication related activities through computers with other organizations. Communication related activities should be increased in order to get benefited with use of computers, and to make financial and administrative activities easier.

Financial activities were highly correlated with administration $(r=0.76328)$ and with education and research $(r=0.70391)$ activities. Managing financial activities with the help of computers will lead to effective administration system. Hence, managing financial activities effectively can make healthcare organizations to spend more money for education, training and research.

Planning and policy development was highly correlated with finance $(r=0.91361)$, with communication $(r=0.88865)$, with education and research $(r=0.80250)$ and with administrative activities $(0.79676)$. Proper planning and policy development such as clinical decision support system (CDSS), patient care planning, policy development, hospital services and planning, health marketing and management, maintaining health information system and quality assurance leads to efficient financial management. If the planning and policy development is well structured then communication within and outside the organization becomes much easier and transparent.

If nurses are well educated and trained, then they can play a vital role in planning and policy development. Also proper planning and policy development makes nurses more knowledgeable and expert in their area. A proper planning and policy development makes administrative management easy.

\subsection{Analysis of Variance (ANOVA)}

An analysis of variance is done to find if gender, qualification and age influences the use of computers at the work place.

There were 10 questions based on computer hardware components that determines to the comfort level in use of computer hardware. All the questions have the rating scale of $0-4,0$ being don't know, 1 being not comfortable, 2 being a little comfortable, 3 being comfortable, 4 being very comfortable. The total score of all these 10 questions is the score for comfort level in use of computer hardware at their workplace.

There were 2 questions based on communication using computers that determines to the comfort level in use of communication related activities. All the questions have the rating scale of $0-4,0$ being don't know, 1 being not comfortable, 2 being a little comfortable, 3 being comfortable, 4 being very comfortable. The total score of these 2 questions is the score for comfort level in use of computers for communication related activities.

There were 2 questions based on administrative activities using a computer that determines to the frequency level in use of computers for administrative activities. All the questions have the rating scale of $0-4,0$ being never, 1 being rarely, 2 being sometimes, 3 being often, 4 being very often. The total score of these 2 questions is the score in use of computers for administrative development related activities.

\subsubsection{Gender influence in use of communication related activities using computers}

An ANOVA test was done to check whether there is a significant difference between male and female nurses in use of communication activities using computers. It is found that there is a significant difference between male and female nurses in the use of communication related activities $(F=4.25, P=0.0409)$. The analysis of variance has been shown in table-3.

Table -3. ANOVA test results on gender influence in use of communication related activities

\begin{tabular}{|c|c|c|c|c|c|c|}
\hline Source & Mean score for male & Mean score for female & Sum of Squares & Mean Square & F Value & Pr $>$ F \\
\hline Model & 7.34 & 5.66 & 62.244582 & 62.244582 & 4.25 & 0.0409 \\
\hline Error & & & 2372.877369 & 14.647391 & & \\
\hline Corrected Total & & & 2435.121951 & & & \\
\hline
\end{tabular}


Male nurses are significantly different compare to female nurses in use of communication related activities. From the mean score, it is found that male nurses are more comfortable than female nurses in use of email and web browsers like Mozilla Firefox, Internet explorer etc. They believe that communication can be improved with the help of computers. This may be due to fact that male nurses are more frank than female nurses in use of communication related activities, inside as well as outside the organization. Female nurses may be little shy in nature to communicate outside the organization, so their use of communication tools are less than male nurses. Hence, they feel less comfortable in use of communication tools such as email, web browser compare to male nurses. However, there is no significant difference has been showed in between male and female nurses in use of computer hardware ( $F=0.70, P=0.4026)$, administrative related activities $(F=0.50, P=0.4805)$. Male and female nurses are equally comfortable in use of computer hardware and the frequency in the use of administrative related activities is same among them.

\subsubsection{Qualification level influence in use of computer hardware}

An ANOVA test was done to check whether there is a significant difference between bachelor degree and diploma holder nurses in use of computer hardware. It is found that there is a significant difference between bachelor degree and diploma holder nurses in the use of computer hardware ( $F=9.31, P=0.0001)$. The analysis of variance has been shown in table-4.

Table 4. ANOVA test results on qualification level influence in use of computer hardware

\begin{tabular}{|c|c|l|c|c|c|c|}
\hline Source & Mean score for diploma holder nurses & Mean score for bachelor degree nurses & Sum of Squares & Mean Square & $\mathrm{F}$ Value & Pr $>\mathrm{F}$ \\
\hline Model & 21.790000 & 31.510000 & 3889.20814 & 1944.60407 & 9.31 & 0.0001 \\
\hline Error & & & 33626.66382 & 208.86127 & & \\
\hline Corrected Total & & & 37515.87195 & & & \\
\hline
\end{tabular}

Bachelor degree nurses are significantly different than diploma holder nurses in the use of computer hardware. From the mean score, it is found that bachelor degree nurses are more comfortable than diploma holder nurses in using desktop, laptop, ipad, keyboard, mouse, touch screen, handheld PDA's, USB devices(pen derive), printers and bar codes. This may be due to fact that bachelor nurses have more opportunities to use computers than diploma level nurses because majority of the bachelor nurses possess the good position in the organization, therefore they have more access to computers. Hence, due to less usage of computers diploma holder nurses are not much comfortable in use of computer hardware.

\subsubsection{Qualification level influence in use of communication related activities}

An ANOVA test was done to check whether there is a significant difference between bachelor degree and diploma holder nurses in use of communication related activities. It is found that there is a significant difference between bachelor degree and diploma holder nurses in the use of communication related activities ( $F=9.48, P=0.0001)$. The analysis of variance has been shown in table-5.

Table 5. ANOVA test results on qualification level influence in use of communication related activities

\begin{tabular}{|c|c|c|c|c|c|c|}
\hline Source & Mean score for diploma holder nurses & Mean score for bachelor degree nurses & Sum of Squares & Mean Square & F Value & Pr $>$ F \\
\hline Model & 4.390000 & 6.840000 & 256.455997 & 128.227999 & 9.48 & 0.0001 \\
\hline Error & & & 2178.665954 & 13.532087 & & \\
\hline Corrected Total & & & 2435.121951 & & & \\
\hline
\end{tabular}

Nurses possess bachelor degree are significantly different compare to diploma holder nurses in use of communication related activities. From the mean score, it is found that bachelor degree holder nurses are more comfortable than diploma holder nurses in use of communication related activities. They believe that communication can be improved with the help of computers. Exchange of information will be easier with the help of computers and patient-nurses relationship can be improved. Bachelor degree nurses are more comfortable in using computers for communication within and outside the organization compare to diploma holder nurses. This may be due to fact that majority of the diploma holder nurses are appointed as junior level of nursing services, and they have less chance to use advance technologies than nurses holding bachelor degree nurses. They are more comfortable in using recent technologies for communication like Facebook, 
WhatsApp, WeChat, Email etc. Hence, bachelor degree holder nurses are more comfortable in use of web browser for communication related activities at their workplace.

\subsubsection{Qualification level influence on managing administrative activities using computers}

An ANOVA test was done to check whether there is a significant difference between bachelor degree and diploma holder nurses in use of administrative development related activities. It is found that there is a significant difference between bachelor degree and diploma holder nurses in use of computers for administrative development related activities $(\mathrm{F}=10.32, \mathrm{P}=0.0001)$. The analysis of variance has been shown in table- 6 .

Table 6. ANOVA test results on qualification level influence in managing administrative activities using computers

\begin{tabular}{|c|c|c|c|c|c|c|}
\hline Source & Mean score for diploma holder nurses & Mean score for bachelor degree nurses & Sum of Squares & Mean Square & $\mathrm{F}$ Value & Pr $>\mathrm{F}$ \\
\hline Model & 5.280000 & 7.370000 & 193.142410 & 96.571205 & 10.32 & 0.0001 \\
\hline Error & & & 1506.095395 & 9.354630 & & \\
\hline Corrected Total & & & 1699.237805 & & & \\
\hline
\end{tabular}

Bachelor degree nurses are significantly different than diploma holder nurses. From the mean score, it is found that bachelor degree nurses are using computers more frequently for administrative related activities than diploma holder nurses. Nurses possess bachelor degree are more often use computers for maintaining administrative activities like maintenance of administrative records, clinical reports of patients. This may be due to fact that their level of understanding that use of computers for administrative activities will improve the outcomes is higher than the diploma holder nurses.

\subsubsection{Age influence in use of computer hardware}

An ANOVA test was done to check whether there is a significant difference between age levels of nurses in use of computer hardware. It is found that there is a significant difference among different age groups ( $F=5.02, P=0.0076)$. The analysis of variance has been shown in table-7.

Table 7. ANOVA test results on age level influence in use of computer hardware

\begin{tabular}{|c|c|c|c|c|c|c|c|}
\hline Source & $\begin{array}{c}\text { Mean score for age range 20- } \\
\mathbf{2 5} \text { years }\end{array}$ & $\begin{array}{c}\text { Mean score for age range } \\
\mathbf{2 6 - 3 0} \text { years }\end{array}$ & $\begin{array}{c}\text { Mean score for age } \\
\text { range 31-50 years }\end{array}$ & $\begin{array}{c}\text { Sum of } \\
\text { Squares }\end{array}$ & $\begin{array}{c}\text { Mean } \\
\text { Square }\end{array}$ & $\mathrm{F}$ Value & Pr $>\mathrm{F}$ \\
\hline Model & 30.45 & 25 & 21.3 & 2203.70723 & 1101.85361 & 5.02 & 0.0076 \\
\hline Error & & & & 35312.16472 & 219.33022 & & \\
\hline Corrected Total & & & & 37515.87195 & & & \\
\hline
\end{tabular}

Tukey's test is run to check that which age group is significantly different from other age groups in use of computer hardware. The results of Tukey's Test have been shown in table 7.1.

Table 7.1. Tukey's Test for Computer Hardware

\begin{tabular}{|c|c|c|c|c|}
\hline \multicolumn{5}{|c|}{ Comparisons significant at the $\mathbf{0 . 0 5}$ level are indicated by ***. } \\
\hline Age Comparison & Difference Between Means & Simultaneous $\mathbf{9 5 \%}$ Confidence Limits & \\
\hline 26-30 years\&21-25 years & 5.646 & -0.977 & 12.270 & \\
\hline 31-50 years\&21-25 years & 9.339 & 1.618 & 17.059 & *** \\
\hline 21-25 years\& 26-30 years & -5.646 & -12.270 & 0.977 & \\
\hline 31-50 years\&26-30 years & 3.692 & -5.178 & 12.562 & \\
\hline 21-25 years\&31-50 years & -9.339 & -17.059 & -1.618 & *** \\
\hline 26-30 years\&31-50 years & -3.692 & -12.562 & 5.178 & \\
\hline
\end{tabular}

From the mean score it is clear that nurse group 20-25 years is more comfortable in use of computer hardware than the age group 31-50 years. This may be due to fact that age group 20-25 years is belongs to new generation nurses. They must have gone through the recent computer related technologies in their past. Hence, they must have use computers more frequently than the age group 31-50 years. However, there is no significance difference have been noticed between 
age group 20-25 years and 26-30 years, 26-30 years and 31-50 years in use of computer hardware.

\subsubsection{Age level influence in use of communication related activities}

An ANOVA test was done to check whether there is a significant difference between different age group of nurses. It is found that there is a significant difference between different age groups of nurses in the use of communication related activities ( $\mathrm{F}=4.63, \mathrm{P}=0.0110)$. The analysis of variance has been shown in table-8.

Table 8. ANOVA test results on age level influence in use of communication related activities

\begin{tabular}{|c|c|c|c|c|c|c|c|}
\hline Source & $\begin{array}{c}\text { Mean score for age range } \\
\mathbf{2 0 - 2 5} \text { years }\end{array}$ & $\begin{array}{c}\text { Mean score for age } \\
\text { range 26-30 years }\end{array}$ & $\begin{array}{c}\text { Mean score for age } \\
\text { range 31-50 years }\end{array}$ & $\begin{array}{c}\text { Sum of } \\
\text { Squares }\end{array}$ & Mean Square & $\mathrm{F}$ Value & Pr $>\mathrm{F}$ \\
\hline Model & 17.77 & 15.02 & 14.42 & 366.750995 & 183.375497 & 4.63 & 0.0110 \\
\hline Error & & & & 6370.047786 & 39.565514 & & \\
\hline Corrected Total & & & & 6736.798780 & & & \\
\hline
\end{tabular}

Tukey's test is run to check that which age group is significantly different from other age groups in use of communication related activities. The results of Tukey's Test have been shown in table 8.1.

Table 8.1. Tukey's Test for Communication related Activities

\begin{tabular}{|c|c|c|c|c|}
\hline \multicolumn{5}{|c|}{ Comparisons significant at the $\mathbf{0 . 0 5}$ level are indicated by ** . } \\
\hline Age Comparison & Difference Between Means & Simultaneous $95 \%$ Confidence Limits & \\
\hline 26-30 years $\& 21-25$ years & 2.7925 & -0.0206 & 5.6057 & \\
\hline 31-50 years $\& 21-25$ years & 3.3951 & 0.1160 & 6.6742 & $*$ *** \\
\hline 21-25 years\& $26-30$ years & -2.7925 & -5.6057 & 0.0206 & \\
\hline 31-50 years $\& 26-30$ years & 0.6026 & -3.1648 & 4.3699 & \\
\hline 21-25 years \&31-50 years & -3.3951 & -6.6742 & -0.1160 & $*$ *** \\
\hline 26-30 years $\& 31-50$ years & -0.6026 & -4.3699 & 3.1648 & \\
\hline
\end{tabular}

It is clear from the mean score that age group 20-25 years is more comfortable in use of communication related activities compare to the age group 31-50 years. This may be due to fact that young age group nurses are digital generation nurses. Hence, they are more familiar in use of computer related tools like email, web browser compare to old generation nurses. Hence, age group 21-25 years is more comfortable in use of communication related activities compare to the age group 31-50 years.

\subsubsection{Age level influence on managing administrative activities using computers}

An ANOVA test was done to check whether there is a significant difference between different age group nurses in use of administrative development related activities. It is found that there is a significant difference between different age group nurses in use of computers for administrative development related activities ( $F=14.07, P=0.0000)$. The analysis of variance has been shown in table- 9 .

Table 9. ANOVA test results on age level influence in managing administrative activities using computers

\begin{tabular}{|c|c|c|c|c|c|c|c|}
\hline Source & $\begin{array}{c}\text { Mean score for age range } \\
\mathbf{2 0 - 2 5} \text { years }\end{array}$ & $\begin{array}{c}\text { Mean score for age range 26- } \\
\mathbf{3 0} \text { years }\end{array}$ & $\begin{array}{c}\text { Mean score for age } \\
\text { range 31-50 years }\end{array}$ & $\begin{array}{c}\text { Sum of } \\
\text { Squares }\end{array}$ & $\begin{array}{c}\text { Mean } \\
\text { Square }\end{array}$ & $\mathbf{F}$ Value & Pr $>$ F \\
\hline Model & 7.5 & 5.84 & 4.23 & 252.858628 & 126.429314 & 14.07 & 0.0000 \\
\hline Error & & & & 1446.379176 & 8.983722 & & \\
\hline Corrected Total & & & & 1699.237805 & & & \\
\hline
\end{tabular}

Tukey's test is run to check that which age group is significantly different from other age groups in managing administrative activities using computers. The results of Tukey's Test have been shown in table 9.1. 
Table 9.1. Tukey's Test for managing administrative activities using computers

\begin{tabular}{|c|c|c|c|c|}
\hline \multicolumn{5}{|c|}{ Comparisons significant at the $\mathbf{0 . 0 5}$ level are indicated by ${ }^{* * *}$. } \\
\hline Age Comparison & Difference Between Means & Simultaneous $\mathbf{9 5 \%}$ Confidence Limits & \\
\hline 26-30 years\&21-25 years & 1.6791 & 0.3386 & 3.0196 & $* *$ \\
\hline 31-50 years\&21-25 years & 3.2945 & 1.7320 & 4.8570 & $* * *$ \\
\hline 21-25 years\& 26-30 years & -1.6791 & -3.0196 & -0.3386 & $*$ *** \\
\hline 31-50 years\&26-30 years & 1.6154 & -0.1798 & 3.4106 & \\
\hline 21-25 years\&31-50 years & -3.2945 & -4.8570 & -1.7320 & $*$ *** \\
\hline 26-30 years\&31-50 years & -1.6154 & -3.4106 & 0.1798 & \\
\hline
\end{tabular}

From the mean score, it is found that age group 20-25 years nurses are using computers more frequently for administrative related activities than age group 25-30 and 30-50 years nurses. Nurses belongs to age group 20-25 are more often use computers for maintaining administrative activities like maintenance of administrative records, clinical reports of patients. This may be due to fact that their level of understanding that use of computers for administrative activities is more than the age group 26-30 and 30-50 years because they are digital nurses. So, their experience and usage of computer assisted technologies will be different from old age group of nurses.

\section{Results}

Male nurses are more comfortable in use of communication related activities than female nurses. Male and female nurses are equally comfortable in use of computer hardware and managing administrative activities using computers. Nurses having bachelor degree are more comfortable in use of computer hardware, communication related activities using computers than diploma holder nurses. Use of computers for administrative related activities is more than diploma holder nurses. Age group 20-25 years were found more comfortable in use of computer hardware and communication related activities than 31-50 years age group nurses. Use of computers for administrative related activities is more by age group 20-25 years than the older age groups. Effectiveness in use of computer hardware tools and operating system can be helpful to develop a high information processing skills among nurses. Major advantages have been noticed in use of communication related activities for finance, administration and education and research. Maintaining financial activities with computers leads to better management, education and development process. A good financial system, effective communication, good management, quality of education and research infrastructure will be helpful for designing planning and policy development activities more easily. More instances of using computers for planning and policy development lead to effective financial management, communication, administration and help in education and research.

\section{Conclusion}

Female nurses should be encouraged to use computers more for communication related activities. Training should be given to diploma holder nurses in use of computer hardware and communication related activities using computers. Computer assisted training should be given to the age group 26-30 and 31-50 years to use computer hardware more efficiently. Old group nurses should be encouraged to use computers more frequently for administrative related activities. Hospital should increase nurses' access to computers and help them become familiar with IT early in their career. Better infrastructure, computer based training and continuing education will lead to better financial, administrative, and planning and policy development process. IT trained nurses will increase communication and help improve operational efficiency. The disparity in preparation between male and female nurses to communicate within and outside the organization should be eliminated for healthcare improvement. This will require new approaches to female nurse training incentives provided to increase their IT use and plans for continuing education. Effective IT training programs may benefit individuals to use IT and computers. Improving the level of comfort by providing IT training to nurses may increase the IT use in healthcare. Healthcare professionals may encourage nurses to use IT at their work place by providing them incentives.

\section{References}

Dumas JA, Dietz EO \& Connolly PM (2001). Nurse Practitioner use of computer technologies in practice, Computers in Nursing, 19, 3440.

Emans Evangel Joel Raja, Rajinder Mahal \& Veena Barkat Masih (2004). An Exploratory Study to Assess the Computer Knowledge, Attitude and Skill among Nurses in Health care setting of a Selected Hospital, Ludhiana, Punjab, India. Online Journal of Nursing 
Informatics, 8, 1304-1307.

Grace Ada Ajuwon (2003). Computer and internet use by first year clinical and nursing students in a Nigerian teaching hospital. BMC Medical Informatics and Decision Making ,3,1-7.

Hans Ragneskog \& Linda Gerdnert (2006). Competence in nursing informatics among nursing students and staff at a nursing institute in Sweden. Health Information and Libraries Journal, 23, 126-132.

Jane Peace (2011). Nurses and Health Information Technology: Working With and Around Computers. N C Medical Journal, 72, 317319.

L. W. Kivuti-Bitok (2009). What do nurse managers want computerized? Needs based assessment study of middle and functional level nurse managers at Kenyatta National Hospital, Kenya. Journal of health informatics in developing countries, 3, 6-11.

Mona P. Ternus \& George F. Shuster (2008). Computer Literacy in a Traditional Nursing Program: A 7 Year study to Identify Computer based Skills needed for Success. Journal of Online Learning and Teaching, 4, 24-36.

Marita Koivunen (2009). Acceptance and use of information technology among nurses in psychiatric hospitals. Thesis, 4-75.

Peter Griffiths \& Lucy Riddingtont (2001). Nurses' use of computer databases to identify evidence for practice-a cross-sectional questionnaire survey in a UK hospital. Health Information and Libraries Journal, 18, 2-9.

Robert Eley, Tony Fallon, Jeffrey Soar, Elizabeth Buikstra \& Desley Hegney (2005). Nurses' confidence and experience in using information technology. Australian Journal of Advanced Nursing ,25, 23-35. 